\title{
Formulation, Development and Evaluation of Colloidosomes of Glipizide
}

\section{Hanmant S. Mali ${ }^{1}$, Safiya R. Shaikh², Saurabh D. Joshi ${ }^{3}$, Vishwajit D. Dhaygude ${ }^{4}$, Akshay R. Yadav ${ }^{5}$}

${ }^{1}$ Department of Pharmaceutics, Rajarambapu College of Pharmacy, Kasegaon, Dist-Sangli, Maharashtra, India

2,5 Department of Pharmaceutical Chemistry, Rajarambapu College of Pharmacy, Kasegaon, Dist-Sangli, Maharashtra, India-415404

${ }^{3}$ Adarsh College of Pharmacy, Vita, Dist-Sangli, Maharashtra, India- 415311

${ }^{4}$ Department of Quality Assurance, Tatyasaheb Kore College of Pharmacy, Warananagar, Dist-Kolhapur,

Maharashtra, India-416113

*Corresponding Author Email: 555hanamantmali@gmail.com

\section{Article Info}

Volume 8, Issue 3

Page Number: 741-750

\section{Publication Issue}

May-June-2021

\section{Article History}

Accepted : 12 June 2021

Published :20 June 2021

\section{ABSTRACT}

Glipizide is a potent oral antidiabetic agent, a second generation sulphonyl urea used in lowering blood glucose in patients with type II diabetes mellitus. It has a short half life of 2-4 hours. The objective of the present study was development and evaluation of colloidosomes of glipizide for controlled/sustained drug release. An attempt was made to formulate and evaluate colloidosomes of glipizide as a model drug using water in oil emulsion based method by using $\mathrm{CaCO}_{3}$ with a view to deliver drug at controlled/sustained manner in GIT and consequently into systemic circulation. The prepared colloidosomes were evaluated for particle size, shape and surface morphology, FTIR study, \% yield, zeta potential, SEM, \% drug entrapment efficiency and in-vitro drug release studies. The obtained colloidosomes were found to be discrete and spherical in shape and found to possess mean particle size range of $2228 \mathrm{~nm}$ to $3551 \mathrm{~nm}$. The drug entrapment efficiency was found to be $52.13 \pm 1.2 \%$ to $71.18 \pm 1.25 \%$. Amongst the prepared batches, Glipizide colloidosomes of Batch $\mathrm{C}$ formulation were stable and exhibited good sustained release of the drug for a period of 12 hours. The release profile was compared with alginate gel spheres. This implied that the developed formulations have a potential to deliver the drug in a sustained manner. This outcome from the release profiling strongly recommends that the developed glipizide loaded colloidosomes may prove to be a useful delivery carrier to deliver the drug in controlled release manner which is a prime requirement for the treatment of type II diabetes mellitus.

Keywords: Colloidosomes, Glipizide, Antidiabetic agent sustained release, Invitro drug release. 


\section{INTRODUCTION}

Vesicular delivery system gives proficient method for delivery of drug directly to the site of infection, prominent to reduction of drug. Vesicular drug delivery reduces the cost of therapy by improved bioavailability of medication, especially in case of poorly soluble drugs. In the past few decades, consequently a number of lipid based systems like lipospheres ${ }^{1}$, liposomes, niosomes, ethosomes, transferosomes were developed.Such drug delivery systems are used for delay drug elimination of rapidly metabolizable drugs and function as sustained release systems. This system also solves the problem of insolubility, instability, rapid degradation ${ }^{2}$. Colloidosomes is an advanced tool in drug delivery. It is novel class of microcapsules whose shell consists of coagulated or fused colloid particles at interface of emulsion droplet. The particles self-assemble on the surface of droplets to minimize the total interfacial energy forming colloidosomes ${ }^{3}$. Colloidosomes are based on Pickering emulsions. Emulsion droplet stabilized by colloid particles at interface of colloidal particles, which are then locked in place on the droplet surface by sintering or some colloidal instability ${ }^{4}$. Colloidosomes are mostly based on the self-assembly of colloidal particles at the interface between twoimmiscible liquids, typically water and oil. The initial self-assembled structures are known as pickeringemulsions ${ }^{5}$ and have been recognized for over a century. Different examples of colloidal particles such as silica solution ${ }^{6-7}$. and polystyrene latexes have been shown to beeffective pickering emulsifiers $^{8}$. According to their elasticity of tuning the permeability over a broad size range, colloidosomes, microcapsules developed by shells of close-packed colloidal particles, have recently been recognized as promising probable vehicles. The most important advantage is that the shell pore size can be adjusted by varying the particle size and by controlling the degree of fusion or coagulation therefore; the colloidosomes may find applications as delivery vehicles for drugs, cosmetics, food additives and living cell ${ }^{9}$. Selectively permeable capsules composed of colloidal particles. The intrinsic porosity of colloidosomes can potentially be used for targeted delivery and controlled release of, for example, drugs $^{10}$. Due to the high energy of desorption of particles from soft interfaces, colloidosomes are surprisingly stable structures ${ }^{11}$. Glipizide is a second generation sulfony-lurea which lowers the blood glucose levels in patient suffering from non-insulin dependent diabetes mellitus (NIDDM), through stimulating insulin secretion from the pancreatic islets of Langerhans, and several other extra pancreatic effects, such as enhancing sensitivity to insulin and decreasing the hepatic glucose production. Glipizide appears to be the most effective insulin secretogogue both in the primary phase of insulin secretion and in sustained stimulatory response during long term administration ${ }^{12-18}$. Possessing unserious side effects and imposing low therapeutic costs have promoted the physicians to prescribe glipizide more than ever ${ }^{19-28}$. As a second generation sulfonylurea, the drug presents fewer side effects compared to the first generation medications and other oral hypoglycemic drugs, while the only side effects of the drug, hypoglycemia and weight gain, are much milder with glipizide compared to the other second generations. Besides, unlike other sulfonylureas, glipizide can be administered for patients with renal impairment should the clearance of creatinine be equal to, or more than $10 \mathrm{ml} / \mathrm{min}^{29-32}$.

\section{MATERIALS AND METHODS}

\section{Materials}

Glipizide was kindly supplied by Micro labs Ltd Bangalore, India; Colloidal particle-Calcium carbonate was purchased from Molychem Chemicals Mumbai. Sodium alginate was procured from Himedia Laboratories Pvt. Ltd Mumbai. Sunflower oil was purchased from Germin seeds Pvt. Ltd. Bangalore. Distilled water, Ethanol and other solvents were 
purchasedfrom local suppliers. All the chemicals were used as supplied, without further purification.

\section{Formulation of Colloidosomes ${ }^{33-38}$}

Selection of concentration of ingredients by preparing blank colloidosomes

The blank colloidosomes were developed so as to optimize the particle size, particle shape.Based on the results of above defined characteristics the selected concentrations of excipientswere optimized and are shown below in table no. 1

\section{Preparation of Blank Colloidosomes}

Blank colloidosomes were prepared by using oil-inwater emulsion based method. In a typical fabrication $\mathrm{CaCO}_{3}$ microparticles were dispersed in sunflower oil through stirring for1 hour. Aqueous solution of sodium alginate was added into oil and oil-in-water emulsion was formed by stirring for several minutes. The emulsion was shaken for two hours and thenleft for $48 \mathrm{~h}$. The obtained colloidosomal dispersion added to non aqueous phase (ethanol)and allowed to centrifuge to separate them from the supernatant. The obtained oil corecolloidosomes are washed with ethanol and finally redispersed in water.

\section{Preparation of Glipizide loaded Colloidosomes}

The formulation chart for formulating Glipizide loaded colloidosomes is shown in following table. Colloidosomes of Glipizide were prepared by oil-inwateremulsion based method.

Table 1: Formulation table for Blank Colloidosomes

\begin{tabular}{|c|c|c|c|c|c|}
\hline $\begin{array}{l}\text { Blank } \\
\text { Formulation }\end{array}$ & $\begin{array}{l}\text { Oil and } \\
\text { water ratio }\end{array}$ & $\begin{array}{l}\text { Sodium } \\
\text { alginate }\end{array}$ & CaCO3 $(\mathbf{m g})$ & $\begin{array}{l}\text { Particle size in } \\
(\boldsymbol{\mu m})\end{array}$ & Particle shape \\
\hline B1 & $1: 4$ & $1 \%$ & 40 & 102.11 & Spherical \\
\hline B2 & $1: 5$ & $1 \%$ & 40 & 98.23 & Spherical \\
\hline B3 & $1: 6$ & $1 \%$ & 40 & 95.45 & Spherical \\
\hline B4 & $2: 4$ & $1 \%$ & 40 & 89.23 & Spherical \\
\hline B5 & $2: 5$ & $1 \%$ & 40 & 85.42 & Spherical \\
\hline B6 & $2: 6$ & $1 \%$ & 40 & 71.24 & Spherical \\
\hline B7 & $3: 4$ & $1 \%$ & 40 & 65.34 & Spherical \\
\hline B8 & $3: 5$ & $1 \%$ & 40 & 47.32 & Spherical \\
\hline B9 & $3: 6$ & $1 \%$ & 40 & 42.24 & Spherical \\
\hline
\end{tabular}

Table 2: Formulation Table of Glipizide loaded Colloidosomes

\begin{tabular}{|c|c|c|c|c|}
\hline Formulation & Drug (mg) & oil and water ratio & Sodium alginate & CaCO3 (mg) \\
\hline B1 & 50 & $1: 4$ & $1 \%$ & 40 \\
\hline B2 & 50 & $1: 5$ & $1 \%$ & 40 \\
\hline B3 & 50 & $1: 6$ & $1 \%$ & 40 \\
\hline B4 & 50 & $2: 4$ & $1 \%$ & 40 \\
\hline
\end{tabular}




\begin{tabular}{|c|c|c|c|c|}
\hline B5 & 50 & $2: 5$ & $1 \%$ & 40 \\
\hline B6 & 50 & $2: 6$ & $1 \%$ & 40 \\
\hline B7 & 50 & $3: 4$ & $1 \%$ & 40 \\
\hline B8 & 50 & $3: 5$ & $1 \%$ & 40 \\
\hline B9 & 50 & $3: 6$ & $1 \%$ & 40 \\
\hline
\end{tabular}

\section{Evaluation of Glipizide Loaded Colloidosomes ${ }^{39-48}$ Percentage yield}

The practical percentage yield was calculated from the weight of colloidosomes recovered from each batch in relation to the sum of the initial weight of starting materials. Thepercentage yield was calculated using the following formula:

Practical Mass (Colloidosomes)

$$
\begin{gathered}
\text { X } 100 \\
\text { Theoretical Mass (Polymer + Drug). }
\end{gathered}
$$

\section{Particle size Analysis}

Particle size of the prepared Colloidosomes was determined by optical microscopy. The Optical microscope was fitted with an ocular micrometer and a stage micrometer. The eyepiece micrometer was calibrated. The particle diameters of 50 Colloidosomes were measured randomly by optical microscope.The average particle size was determined by using the Edmondson's equation:

$$
\text { Edmondson's equation: }=\frac{€ n d}{£ \mathrm{n}}
$$

Where, $\mathrm{n}$ - Number of colloidosomes observed $\mathrm{d}$ - Mean size range

\section{Determination of Entrapment Efficiency Percentage}

Entrapment efficiency of Glipizide loaded Colloidosomes was estimated by centrifugation method. The prepared Colloidosomes were placed in centrifugation tube and centrifuged at $15000 \mathrm{rpm}$ for $30 \mathrm{~min}$. The supernatant $(1 \mathrm{ml})$ was withdrawn and diluted with ethanol. The unentrapped Glipizide was determined by UV spectrophotometer at $230 \mathrm{~nm}$. The samples from the supernatant were diluted suitably before going for absorbance measurement. The free Glibenclamide in the supernatant gives the total amount of unentrapped drug. Encapsulation efficiency is expressed as the percent of drug trapped and was calculated using below equation no. Concentration of drug was calculated from equation of straight line obtained for standard curve for Glibenclamide.

Total amount of drug - Free dissolved drug $\%$ E.E $=$

$$
-\mathrm{X} 100
$$

\section{Total amount of drug}

\section{Shape and surface morphology}

Scanning electron microscopy was done to study the particle surface morphology and shape. The sample for the SEM analysis was prepared by sprinkling the colloidosomes on to one side of double-adhesive stub. The stub was then coated with gold using Jeol JFC 1100 sputter coater (Jeol Ltd, Tokyo, Japan). The SEM analysis of the colloidosomes was carried out by using Jeol JSM 5300 (Jeol Ltd). The colloidosomes were viewed at an accelerating voltage of $15-20 \mathrm{kV}$.

\section{Zeta Potential Determination}

Zeta potential was measured by using Zetatrac after appropriate dilution with distilled deionised water.

\section{In-Vitro Drug Release Studies}

Colloidosomes equivalent to $5 \mathrm{mg}$ of Glipizide was taken in to tube with both ends open. One end of the tube is closed with dialysis membrane. Now the tube containing drug loaded Colloidosomes is kept in a 
beaker containing buffer $\mathrm{pH} 1.2$ (for initial 2 hours later then the medium was changed to $\mathrm{pH} 7.4$ phosphate buffer solutions and drug release was studied for further remaining hours.). The tube is arranged in such a way that, it just touches the surface of the buffer solution. The whole set up is placed on a magnetic stirrer and rotated at $75 \mathrm{rpm}$. The temperature of buffer is maintained at $37 \pm 0.50 \mathrm{C}$. At prefixed time (every 1 hour); $1 \mathrm{ml}$ of solution were withdrawn. After suitable dilution, samples were assayed spectrophotometrically for the drug content at $230 \mathrm{~nm}$ using UV Visible spectrophotometer.

\section{RESULTS AND DISCUSSION}

\section{Percentage Yield}

The $\%$ yields of all 9 formulations were very high for all colloidosomes obtained and were not affected by the type of polymer, the polymer: drug ratio, the stirring speed of the system and the ratio of the mixture of polymers. The yields of all formulations are shown in Table no. 3.

\section{Percentage Drug entrapment efficiency}

The \% drug entrapment efficiency of Glipizide ranged from 65.88 to $76.28 \%$ for colloidosomes of Glipizide using sodium alginate. It was seen that highest entrapment efficiency; when oil and water ratio maintained 2:6. Beyond this ratio when concentration increased the entrapment efficiency was found to be decreased. The reason for this is, during the cross linking process, the Colloidosomes will shrink and expel the drug molecules along with the water into the oil phase. This could be the reason for the loss of $10-20 \%$ of the drug during the encapsulation process. Moreover, higher drug loading lowered the percentage of entrapment and encapsulation, which indicates the wastage of drug during the microencapsulation process.

\section{Particle size Analysis}

The mean particle size ranged from $45 \mu \mathrm{m}-115.14$ $\mu \mathrm{m}$.The mean size was influenced by the concentration of water volume used in the formulation. As the volume fraction of water varies, some colloidosome deformed to nonspheral shape and even broken, also significant effect of stirring speed was observed for all formulations. This may be due to the less availability of amphiphiles during emulsion formation and maybe partly due to more partitioning of surfactant in to oil phase as the concentrations ofaqueous phase was increased. Further as the stirring speed was raised there is decrease in average particle size of colloidosomes. This is due to high stress generated at the interface causing more creation of new surfaces which were appropriately stabilized by amphiphiles resulting in smaller particle size distribution. Mean particle size of all formulations are givenin the Table no.3.

Table 3: \% Yield, \% Drug entrapment efficiency, Particle size of Colloidosomes of Glipizide

\begin{tabular}{|c|c|c|c|}
\hline Formulation code & \% Yield & $\begin{array}{c}\text { \% Drug entrapment } \\
\text { efficiency }\end{array}$ & Particle size $(\mu \mathrm{m})$ \\
\hline F1 & $81.33 \pm 2.1$ & $74.48 \pm 2.1$ & $115.14 \pm 2.2$ \\
\hline F2 & $82.74 \pm 1.4$ & $71.15 \pm 2.4$ & $113.34 \pm 3.2$ \\
\hline F3 & $79.88 \pm 2.1$ & $69.44 \pm 3.2$ & $107.88 \pm 4.3$ \\
\hline F4 & $78.78 \pm 3.2$ & $71.39 \pm 3.2$ & $91.8 \pm 3.1$ \\
\hline F5 & $81.95 \pm 2.3$ & $65.88 \pm 0.98$ & $87.96 \pm 1.1$ \\
\hline F6 & $82.11 \pm 2.1$ & $76.28 \pm 4.3$ & $72.84 \pm 2.3$ \\
\hline F7 & $81.32 \pm 3.1$ & $74.46 \pm 2.1$ & $70.32 \pm 1.4$ \\
\hline
\end{tabular}




\begin{tabular}{|c|c|c|c|}
\hline F8 & $82.14 \pm 2.2$ & $73.39 \pm 1.3$ & $49.5 \pm 3.2$ \\
\hline F9 & $81.67 \pm 1.4$ & $73.18 \pm 1.2$ & $45.0 \pm 2.1$ \\
\hline
\end{tabular}

\section{Shape and Surface Morphology}

Morphology of the colloidosomes was investigated by scanning electron microscopy. Colloidosomes of Glibenclamide were spherical and their surface was smooth and devoid of cracks giving them good appearance. The SEM data obtained on the drug-loaded colloidosomes are shown in figure.

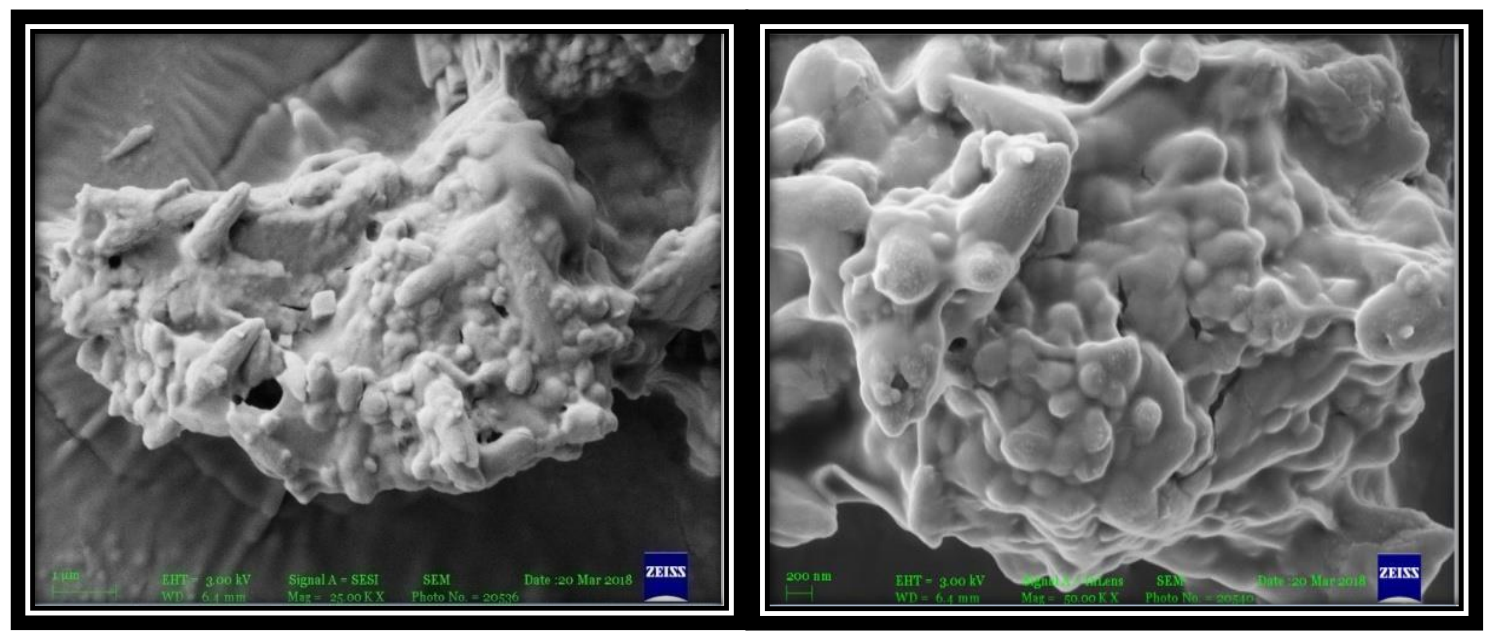

\section{Zeta Potential}

Fig No.1: (a) and (b) SEM photograph of prepared Colloidosomes of Glipizide

The stability of the drug delivery system was assessed by measuring the zeta potential of the particles by Zetatrac. If all the particles in a suspension have a large positive or negative zeta potential then they will tend to repel each other and there will be no tendency for the particles to come together. Zeta potential values of 9 formulations are presented in table no. 4

Table 4: Zeta potential values

\begin{tabular}{|c|c|}
\hline FormulationCode & Zeta potential ${ }^{*}(\mathrm{meV})$ \\
\hline F1 & $-18 \pm 1.1$ \\
\hline F2 & $-15 \pm 0.9$ \\
\hline F3 & $-19 \pm 13$ \\
\hline F4 & $-21 \pm 1.2$ \\
\hline F5 & $-23 \pm 1.6$ \\
\hline F6 & $-28 \pm 1.5$ \\
\hline F7 & $-26 \pm 1.5$ \\
\hline F8 & $-25 \pm 1.4$ \\
\hline F9 & $-22 \pm 1.3$ \\
\hline
\end{tabular}

${ }^{*}$ Each value represented as mean \pm Standard Deviation of 3 observations values in comparison to other formulations. The high

The zeta potential values of Glipizide loaded Colloidosomes were found in the range of -15 to -28 . The formulation F6 shows highest Zeta potential zeta potential value indicates high stability. This study confirms the stability characteristics of developed formulations. 


\section{In-Vitro Drug Release Studies}

In Vitro drug release studies of all the Colloidosomes formulations were carried out in a two different buffers, $\mathrm{pH} 1.2$ and $\mathrm{pH} 7.4$ using dialysis membranes. The study was performed for $8 \mathrm{hrs}$, and cumulative drug release was calculated at different time intervals. It was observed that the drug release from the formulations slightly increases as the particle size of the formulation decreases. All the formulation released the drug up to 8 hours which was very significant as compared with the marketed formulation Daonil which released nearly 100\% drug within 6 hours. The release profile depicted in the figure no. 3 shows that the developed colloidosomes formulations were found to retard the drug release in comparison to marketed formulation Daonil. To ascertain the release mechanism the release data was fitted in four different kinetic models, namely.

\section{CONCLUSION}

According to the studies, colloidosomes have a good performance for loading the anti-diabetic drug Glipizide. As the study showed that prepared formulation good surface morphology and loading efficiency. All prepared colloidosomes were discrete, spherical in shape, and had good surface morphology, according to SEM examination. The presence of a high zeta potential value suggests a high level of stability. This study confirms the stability characteristics of developed colloidosomes formulations. By varying the oil water ratio, it was found that Increase in water concentration in formulation leads to increase in particle size, percent entrapment efficiency and slower release rate. The drug release from the formulations increases marginally as the particle size of the formulation decreases, according to an in vitro drug release research. The release mechanism of the formulations was confirmed using kinetic models. Glipizide release followed zero order kinetics in all formulations. The considerable barrier presented by the partitioning of the medication in the oil phase to the water phase is responsible for the delay in release. The colloidal particle $\mathrm{CaCO}_{3}$ adsorbed at the interface gave the formulation more stiff properties and potentiated the delayed drug release from the formulation. This means that newly developed formulations may be able to distribute the drug in a controlled manner. The results of the release profiling strongly suggest that the developed Glipizide-loaded colloidosomes could be a useful delivery carrier for delivering drugs in a controlled release manner, which is essential for the treatment of diabetes mellitus.

\section{REFERENCES}

[1]. Chowdary KPR, Srinivasa YR. Design and in vitro evaluation of mucoadhesive controlled release oral tablet of glipizide. Indian J Pharm. 2003; 65: 592-599.

[2]. Thombre AG, Denoto AR, Gibbes DC. Delivery of glipizide from asymmetric membrane capsules using encapsulated excepients. J control release. 1999; 60: 333-341.

[3]. Rendell M. The role of sulphonylureas in the management of type 2 diabetes mellitus. Drugs. 2004; 64:1339-1358.

[4]. Verma RK, Garg S. Development and evaluation of osmotically controlled oral delivery system of glipizide. Eur J Pharm Biopharm. 2004;57: 513525 .

[5]. Dhadde G.S, Yadav J.P , Sapate R.B, Mali H.S, Raut I.D, In vitro Anthelmintic Activity of crude extract of flowers of Bougainvillea Spectabilis Wild against Pheretima Posthuma, International Journal of Pharmacy and Pharmaceutical Research, 2020; 17: 1-18.

[6]. Akanksha Jagdale, Dr. Sandeep Patil, Hanmant Mali, Snehal Chandanshive, In-vitro Antispasmodic Efficiency of Ethanolic Extract of Leaves of Sesbania Grandiflora, World 
Journal Of Pharmaceutical Research, 2020; 9(2): 915-921.

[7]. Dhadde Gurunath S., Mali Hanmant S., Sapate Rohit B., Vakhariya Rohan R., Raut Indrayani D., Nitalikar Manoj M., Investigation of InVitro Anthalmintic Activity of Methanolic Extract of Tylophora Indica Leaves Against Haemonchus Contortus, Journal of University of Shanghai for Science and Technology, 2021; 23(2): 37-42.

[8]. Modi Kushal, Modi Monali, Mishra Dugavati, Panchal Mittal, Sorthiya Umesh, Shelat Pragna; oral controlled release drug delievery system an overview,Int j. Pharm. 2013; 4(3): 70-76.

[9]. Yadav A, Mohite S. Aquasomes as a Self Assembling Nanobiopharmaceutical Carrier System for Bio-Active Molecules. Research J. Topical and Cosmetic Sci. 2020; 11(2): 66-70.

[10]. Yadav A, Mohite S. Potential Role of Peptides for Development of Cosmeceutical skin Product. Research J. Topical and Cosmetic Sci. 2020; 11(2): 77-82.

[11]. Rawat, M., S. Saraf; Liposphere: Emerging carriers in the delivery of proteins and peptides, Int. J. Pharm. Sci. Nanotechnol. 2008; 1: 207214.

[12]. Horcajada P, Chalati T, Serre C, et al. Porous metal-organic-framework nanoscale carriers as a potential platform for drug delivery and imaging. Nat Mater. 2010;9(2):172-178.

[13]. Yadav A, Mohite S. Applications of Nanotechnology in Cosmeceuticals. Research J. Topical and Cosmetic Sci. 2020; 11(2): 83-88.

[14]. Slowing II, Vivero-Escoto JL, Wu CW, et al. Mesoporous silica nanoparticles as controlled release drug delivery and gene transfection carriers. Adv Drug Deliv Rev. 2008; 60(11):1278-1288.

[15]. Kidane A, Bhatt PP. Recent advances in small molecule drug delivery. Curr Opin Chem Biol. 2005;9(4):347-351
[16]. Yadav A, Mohite S. Recent advances in protein and peptide drug delivery. Res. J. Pharma. Dosage Forms and Tech. 2020; 12(3): 205-212.

[17]. Baily CJ. Potential new treatments for type two diabetes. Tips. 2000; 21: 259-265.

[18]. Rawat, M., S.S. Reader; Formulation optimization of double emulsification method for preparation of enzyme-loaded Eudragit S100 microspheres, J. Microencapsulation. 2009; 26: 306-314.

[19]. Rawat, M., D. Singh, S. Saraf, S. Saraf; Lipid carriers: A versatile delivery vehicle for proteins and peptides. Yakugaku Zasshi. 2008; 128: 269280.

[20]. Chanchal, D., S. Swarnlata; Novel approaches in herbal cosmetics, J. Cosmet. Dermatol., 2008; 7: 89-95.

[21]. Honmane P, Yadav A, Singh S, Mohite S. 3D printing technology in pharmaceuticals and biomedical. World J Pharm Pharm Sci. 2020; 9(9): 598-609.

[22]. Yow HN, Routh AF. Formation of Liquid core polymer shell microcapsules. Soft Matter. 2006; 2: 940-949.

[23]. Salunkhe K, Yadav A. Recent Advances in Manufacturing Technologies and Future Prospects of Mouth Dissolving Tablets (FDTs). International Journal of Scientific Research in Chemistry. 2020; 5(2): 26-32.

[24]. Elsayed, M.M.A., O.Y. Abdullah, V.F. Naggar, N.M. Khalafallah; Deformable liposome and ethosome: Mechanism of enhanced skin delivery, Int. J. Pharm.,2006; 322: 60-66.

[25]. Biju, S.S., S. Talegaonkar, P.R. Mishra, R.K. Khar; Vesicular system: An overview, Ind. J. Pharm. Sci.,2006; 68: 141-153.

[26]. Dhadde Gurunath S., Mali Hanmant S., Raut Indrayani D., Nitalikar Manoj M.,Bhutkar Mangesh M., A Review on Microsphere: Types, Method of Preparation, Characterization and Application, Asian Journal of Pharmacy and Technology, 2021; 11(2):149-155. 
[27]. Thompson KL, Williams M, Armes SP. Colloidosomes: Synthesis, properties and applications. J Colloid Interface Sci. 2015; 447: 217-228.

[28]. Suryawanshi V, Yadav A, Birajdar R. Optimization of Ayurvedic Herbal Medicine by Nanoformulation. Asian Journal of Research in Pharmaceutical Sciences. 2019; 9(1): 55-56.

[29]. Fabrication of Novel Types of Colloidosome Microcapsules for Drug Delivery Applications Materials Research Society Symposium Proceedings. Volume 845, 2005.

[30]. Nanoscale Materials Science in Biology and Medicine, Held in Boston, MA on 28 November-2 December 2004.

[31]. Hongxia Liu, Chaoyang wang, Quanxing Gao, Xinxing Liu, Zhen Tong; Fabriction of novel core-shell hybrid alginate beads, International journal of pharmaceutics. 2008: 104-112.

[32]. Suryawanshi V, Yadav A, Birajdar R. Optimization of Ayurvedic Herbal Medicine by Nanoformulation. Asian Journal of Research in Pharmaceutical Sciences. 2019; 9(1): 55-56.

[33]. Yadav A, Mohite S. Formulation and Evaluation of Antidandruff Shampoo. Research Journal of Topical and Cosmetic Sciences. 2020; 11(2): 5558.

[34]. Douliez JP, Martin N, Beneyton T, et al. Preparation of swellable hydrogel-containing colloidosomes from aqueous two-phase Pickering emulsion droplets. Angew Chem. 2018; 130: 7906-7910.

[35]. Yadav A. Preparation and Evaluation of Herbal Mouthwash containing Psidium guajava Leaf Extract. International Journal of Pharmaceutical Research and Development. 2020; 2(1): 24-26.

[36]. Das M K and Maurya D Evaluation of Diltiazem hydrochloride loaded mucoadhesive microspheres prepared by emulsificationinternal gelation technique. Acta Poloniae Pharmaceutica Drug Research. 2008; 65(2); 249259.
[37]. Yadav A, Raut I, Vakhariya R. Formulation \& Evaluation of Herbal Lipstick using Morus alba Linn. International Journal of Pharmacy and Pharmaceutical Science. 2020; 2(1): 04-05.

[38]. Binks BP. Particles as surfactants - similarities and differences. Curr Opin Colloid Interface Sci. 2002;7(1-2):21-41.

[39]. Patil S, Yadav A, Chopade A, Mohite S. Design, Development and Evaluation of Herbal Mouthwash for Antibacterial Potency against Oral Bacteria. Journal of University of Shanghai for Science and Technology. 2020; 22(11): 881898.1137-1148.

[40]. Rosenberg RT, Dan NR. Diffusion through colloidosome shells. J Colloid Interface Sci. 2011; 354(2):478-482.

[41]. Honmane P, Mali V, Mali A, Mahadik P, Yadav A, Mohite S. Formulation and Evaluation of Herbal Ointment Containing Eclipta Alba (L.) Extract. Journal of Seybold Report. 2020; 25(10): 569-577.

[42]. Dhadde Gurunath S., Mali Hanmant S., Raut Indrayani D., Nitalikar Manoj M., An Overview on Multiple Emulsions, Asian Journal of Pharmacy and Technology, 2021; 11(2): 156158.

[43]. Dange V, Dinde S, Doiphode A, Dhavane S, Dudhal B, Shid S, Yadav A. Formulation and Evaluation of Herbal gel Containing Lantana Camara for Management of Acne Vulgaris. Journal of University of Shanghai for Science and Technology. 2020; 22(11): 799-809.

[44]. Keen PHR, Slater NKH, Routh AF. Encapsulation of yeast cells in colloidosomes. Langmuir. 2012; 28(2): 1169-1174.

[45]. Sun Q Gao H, Sukhorukov GB, et al. Silvercoated colloidosomes as carriers for an anticancer drug. ACS Appl Mater Interfaces. 2017; 9(38): 32599-32606.

[46]. Sun Q Du Y, Hall EAH, et al. A fabrication method of gold coated colloidosomes and their 
application as targeted drug carriers. Soft Matter. 2018; 14(14): 2594-2603.

[47]. Guan BY, Yu L, Lou XW. Chemically assisted formation of monolayer colloidosomes on functional particles. Adv Mater. 2016; 28: 95969601.

[48]. Miguel AS, Behrens SH. Permeability control in stimulus-responsive colloidosomes. Soft Matter. 2011; 7(5): 1948-1956.

\section{Cite this article as :}

Hanmant S. Mali, Safiya R. Shaikh, Saurabh D. Joshi, Vishwajit D. Dhaygude, Akshay R. Yadav, "Formulation, Development and Evaluation of Colloidosomes of Glipizide", International Journal of Scientific Research in Science and Technology (IJSRST), Online ISSN : 2395-602X, Print ISSN : 23956011, Volume 8 Issue 3, pp. 741-750, May-June 2021. Available at doi: https://doi.org/10.32628/IJSRST2183141 Journal URL : https://ijsrst.com/IJSRST2183141 